\title{
FACILITADORES, DIFICULTADORES E PRINCIPAIS FOCOS DE CONFLITO DO PROCESSO SUCESSÓRIO
}

\section{FACILITATORS, DIFFICULTY AND MAIN CONFLICT OF THE SUCCESSORY PROCESS}

\section{FACILITADORES, DIFICULTADES Y PRINCIPALES FOCOS DE CONFLICTO DEL PROCESO SUCESARIO}

\section{Andreia Aparecida Pandolfi dos Santos}

Mestra em Administração pela Universidade do Sul de Santa Catarina (UNISUL)

Professora no Centro Universitário Leonardo da Vinci (UNIASSELVI)

Endereço: Uniasselvi, Rod. BR-470, Km 71, 1.040 - Benedito, CEP: 89130-000. Indaial, SC, Brasil

Telefone: (47) 32819000

E-mail: andripandolfi@yahoo.com.br

\section{Simone Sehnem}

Doutora em Administração e Turismo, Universidade do Vale do Itajaí (UNIVALI)

Professora dos Programas de Pós-Graduação em Administração da Universidade do Oeste de Santa Catarina (UNOESC), e Universidade do Sul de Santa Catarina (UNISUL)

Endereço: UNISUL, R. Adolfo Melo, n. 34, Centro, CEP: 88015-090. Florianópolis, SC, Brasil

Telefone: (48) 3279-1932

E-mail: simone.sehnem@unoesc.edu.br

\section{Gleberson de Santana dos Santos}

Mestre em Administração pela Universidade do Oeste de Santa Catarina (UNOESC)

Professor substituto na Faculdade de Administração e Turismo da Universidade Federal de Pelotas e professor assistente nos cursos de pós-graduação da Faculdade de Tecnologia SENAC

Endereço: UNISUL, R. Adolfo Melo, n. 34, Centro, CEP: 88015-090. Florianópolis, SC, Brasil

Telefone: (48) 3279-1932

E-mail: glebersonsantana@hotmail.com

Artigo recebido em 11/03/2018. Revisado por pares em 09/07/2018. Reformulado em 15/07/2018. Recomendado para publicação em 20/07/2018. Publicado em 01/08/2018. Avaliado pelo Sistema double blind review. 


\section{RESUMO}

Este artigo buscou analisar os aspectos facilitadores, dificultadores e principais focos de conflito do processo sucessório de uma empresa familiar considerada de grande porte. Metodologicamente, trata-se de um estudo de caso único, com abordagem qualitativa e enfoque descritivo. A coleta de dados foi realizada por meio de entrevistas semiestruturadas e pesquisa documental. Conclui-se que o caso apresentou bem mais aspectos facilitadores do que dificultadores na condução dos processos, entre eles: o planejamento sucessório à longo prazo, programa de incentivo e de formação de lideranças incorporado à cultura, a formalização da governança corporativa, a preparação e a orientação para os herdeiros.

Palavras-chave: Aspectos facilitadores; Aspectos dificultadores; Empresa familiar; Processo sucessório.

\section{ABSTRACT}

This article aimed to analyze the facilitators and difficulties aspects and main focuses of conflict of the succession process of a family company considered of great size. Methodologically, this is a unique case study, with a qualitative approach and a descriptive approach. Data collection took place through semi-structured interviews and documentary research. It is concluded that the case presented much more facilitating aspects than difficulties aspects in the conduct of the processes, among them: long-term succession planning, incentive program and formation of leaderships incorporated to culture, corporate governance formalization, preparation and guidance to the heirs.

Keywords: Facilitators aspects; Difficulties aspects; Family business; Succession process.

\section{RESUMEN}

Este artículo buscó analizar los aspectos facilitadores, dificultadores y principales focos de conflicto del proceso sucesorio de una empresa familiar considerada de gran porte. Metodológicamente, se trata de un estudio de caso único, con abordaje cualitativo y enfoque descriptivo. La recolección de datos fue realizada por medio de entrevistas semiestructuradas e investigación documental. Se concluye que el caso presentaba mucho más aspectos facilitadores que dificultantes en la conducción de los procesos, entre ellos: la planificación sucesoria a largo plazo, programa de incentivo y de formación de liderazgos incorporado a la cultura, la formalización del gobierno corporativo, la preparación y la orientación hacia los herederos.

Palabras clave: Aspectos facilitadores; Aspectos difíciles; Empresa familiar; Procedimiento de sucesión. 


\section{INTRODUÇÃO}

O ápice das empresas familiares no Brasil se deu a partir da Segunda Guerra Mundial, com a chegada de imigrantes provenientes de diversos países, como Itália, Alemanha, Portugal, Polônia e Japão, entre outros. Esses indivíduos vieram para o Brasil para fugir dos movimentos nazista e fascista que proliferavam na Europa e, principalmente, vinham em busca de melhores condições de vida. No mundo ocidental, houve um aumento na quantidade de negócios familiares que resultou no crescimento econômico, a partir da década de 1950 e, especialmente, ao longo das décadas de 1960 e de 1970, quando surgiu a maioria das empresas sob propriedade de famílias (BUENO; FERNÁNDEZ; SÁNCHEZ, 2007; MORAIS FILHO, 2009).

Dados da Family Business Network (FBN, 2015) revelaram que 63\% das empresas familiares brasileiras, ainda, não desenvolveram nenhum tipo de planejamento sucessório, nesse estudo mencionou-se que, para evitar problemas na sucessão de uma empresa familiar, é interessante criar e discutir um plano de sucessão, que deve ser elaborado com a previsão de todas as etapas necessárias, incluindo, de forma explícita, a transição, a cogestão e os requisitos para escolha do sucessor. De acordo com estudos da PWC (2015), apenas $11 \%$ das empresas familiares brasileiras têm um plano de sucessão em vigor, robusto e documentado.

O objetivo deste trabalho consiste em: analisar os aspectos facilitadores, dificultadores e principais focos de conflito do processo sucessório de uma grande corporação. buscando verificar como esses aspectos propiciam medidas preventivas para o êxito do processo sucessório, bem como, evidenciando as principais ferramentas estratégias adotadas para a realização dos processos sucessórios, seja esse familiar ou profissional.

Na visão de Hauswald e Hack (2013), a continuidade, a sobrevivência, a estruturação e a longevidade de um negócio são os motivos de apreensão da maioria dos empresários, investidores e executivos, o que ocasiona diversas oportunidades de estudos para pesquisadores entenderem e difundirem as melhores práticas para a consolidação de um negócio. Muitos desses estudos, no entanto, têm sido realizados apenas em pequenas e médias empresas, organizações essas de controle privado e familiar (LANDSTROM; WINBERG, 2000; LEAVELL; MANIAM, 2009).

Revista Eletrônica de Estratégia \& Negócios, Florianópolis, v.11, n. 1, mai./ago. 2018. 
É com base na observação de estudos já realizados nessa temática que se verificou a importância desta pesquisa, pois aqui se estudará uma organização de grande porte que já vivenciou dois processos sucessórios exitosos, logo trata-se da justificativa para o desenvolvimento da pesquisa. Embora crescente o número de publicações sobre empresas familiares, até o devido momento não foram encontrados trabalhos (artigos científicos, dissertações e teses) referenciando exatamente essa temática estudada, efetuados no lócus organizacional da WEG. Essa afirmação é derivada de investigações efetuadas nas seguintes bases de dados: Associação Nacional de Pós-Graduação e Pesquisa em Administração (ANPAD); Ebscohost Research Databases (EBSCO), Scientific Eletronic Library Online (SCIELO), Scientific Periodicals Eletronic Library (SPELL), Science Direct, SCOPUS e Biblioteca Digital Brasileira de Teses e Dissertações (BDTD).

\section{REFERENCIAL TEÓRICO}

Esta seção discute sobre os aspectos facilitadores, dificultadores e focos de conflito da sucessão familiar.

\subsection{FACILITADORES DA SUCESSÃO FAMILIAR}

Lodi (1998), Lee, Lim e Lim (2000), Ward (2006), Sharma (2006) e Machado (2006), em sucintos relatos nas seções anteriores, mencionaram algumas ações e situações sobre os processos facilitadores da sucessão. Porém, mesmo depois de alguns anos, cabe destacar que os estudos realizados por Scheffer (1995) são os mais citados no meio acadêmico nacional quando se trata de pesquisas sobre os fatores dificultadores e facilitadores ao processo de sucessão familiar, assim como suas características, sejam elas negativas, no caso dos dificultadores, ou positivas, no caso dos facilitadores.

Diante das diversas dificuldades existentes no processo sucessório e das incertezas e inseguranças do fundador em dar início ao processo, Gueiros e Oliveira (2000) salientam a necessidade de estabelecer ações preventivas que promoverão o processo sucessório. Essas ações podem facilitar a transição de uma geração para outra e minimizar os problemas relativos aos envolvimentos nesse processo, além de guiar o fundador a planejar seu afastamento gradativo da empresa e a preparar seu futuro sucessor antecipadamente (GUEIROS; OLIVEIRA, 2000). 
Scheffer (1995), em suas pesquisas, destaca alguns fatores facilitadores do processo sucessório em empresas familiares entre eles: o envolvimento da família no processo sucessório. Scheffer (1995, p. 87) completa sugerindo que o envolvimento da família deve vir “[...] principalmente através de discussão e comunicação dos planos a todos os seus membros, ativos ou inativos". Gueiros e Oliveira (2000) advogam sobre a criação de conselhos no âmbito familiar, sugerindo encontros promovidos com as devidas gerações de familiares para buscar um consenso do que será melhor para o futuro da organização. Um fator relevante apresentado por Scheffer (1995), relaciona-se à preparação do sucedido para o processo de sucessão. Esse fator está diretamente ligado ao autoconvencimento do fundador sobre sua importância no processo sucessório e nas devidas providências a serem tomadas após sua aposentadoria.

Na opinião de Cruz Machado, Wetzel e Rodrigues (2008), um dos fatores facilitadores do processo sucessório diz respeito à convivência, desde muito cedo, dos herdeiros e à acessibilidade direta com o presidente da companhia das informações estratégicas que a maioria dos executivos apenas conhece quando chega ao topo. Ainda conforme Cruz Machado, Wetzel e Rodrigues, (2008), o envolvimento intenso dos herdeiros e dos futuros sucessores é de certa forma uma garantia leal e uma mostra de afeição que não seriam encontradas tão facilmente em executivos contratados no mercado.

Salvato, Corbetta (2013) realizaram pesquisa empírica com quatro empresas familiares, consideradas de média a grande porte, com o objetivo de analisar como os consultores especializados facilitam na identificação e na formação de sucessores e como auxiliam na transposição dos processos. Os resultados evidenciaram que a atuação de consultores foi fundamental para o desenvolvimento da liderança do sucessor e para a transição dos processos.

\subsection{DIFICULDADES DO PROCESSO SUCESSÓRIO}

Partindo do princípio de que existem muitos desafios envolvidos e potenciais dificuldades no processo sucessório, Bernhoeft (1989) aponta diversos tópicos que podem ocasionar dificuldades no processo sucessório. Ele menciona as divergências entre os sócios, o excessivo número de sucessores, a falta de uma liderança natural que seja bem aceita, a existência de um desinteresse pelo negócio por parte dos sucessores, as diferenças muito Revista Eletrônica de Estratégia \& Negócios, Florianópolis, v.11, n. 1, mai./ago. 2018. 
marcantes entre as participações acionárias entre os sócios, quando o fundador encara o negócio somente como uma forma de dar segurança para os filhos, além de divergências familiares que se tornam marcantes e de difícil solução. Principalmente quando há um desinteresse do fundador pelo futuro da empresa e dos familiares, o que provoca certa insegurança entre os trabalhadores com relação ao futuro da empresa, quando eles constatam a falta de orientação estratégica e operacional. Lodi (1987) afirma que grande parte das dificuldades encontradas na implementação do processo de sucessão tem origem na falta de conhecimento dos problemas de relacionamento da empresa/família.

Segundo Scheffer (1995), quando um sucessor não possui capacitação para o cargo isso se torna um dos aspectos limitadores para a continuidade das organizações familiares, já que é imprescindível que haja preparação do sucessor, no sentido de habilitação profissional, para que ele obtenha experiência, capacidade e conhecimento suficientes para não tornar a sucessão um fracasso. Caso isso ocorra, os traumas para a empresa e para a família são irreversíveis, além de tal acontecimento criar outras limitações, por exemplo, o sucessor passa a ser rejeitado por parte dos funcionários mais antigos que começam a desvalorizar o Filho, julgando incapacidade em comparação ao pai (SCHEFFER, 1995).

Gueiros e Oliveira (2000) reportam que fatores dificultantes com os quais as empresas familiares se defrontam em suas fases de transição contribuem para o enfraquecimento da estrutura empresarial. Em pesquisas de Scheffer (1995) são definidos seis fatores que podem, de certa forma, dificultar o processo sucessório, dentre eles: Lacunas na capacitação do sucessor, que se referem a desvios no autodesenvolvimento do herdeiro, tanto em sua educação formal quanto em aspectos gerenciais. Scheffer (1995) adverte também que falta de vivência, pouca experiência no exercício da autoridade, despreparo gerencial/administrativo, visão diferenciada do negócio em relação à visão do sucedido e conquista de espaço na empresa devido à influência do sucedido, são as principais variáveis determinantes das lacunas da capacidade do sucessor.

De Massis, Chua e Chrisman (2008) também identificaram em suas pesquisas, os fatores que podem impedir o sucesso da sucessão familiar, por meio de uma revisão literária nas seguintes teorias e abordagens: na empresa familiar, na gestão, nas áreas como a economia, a antropologia, a história, a psicologia, a sociologia e o direito, em revistas que 
apresentam estudos de caso sobre a sucessão familiar, nas mais requisitadas bases de dados contemplando casos como: Europeu Clearing House, casos da Harvard Business School, IveyPublishing, Escola de Gestão, Darden INSEAD, Institutpourl' Etudedes métodos des Direction de l'Enterprise, Instituto Europeu de Administração de Empresas e o caso da investigação oficial até 2005. Os autores por meio de uma revisão tensa na literatura desenvolveram um modelo teórico para determinar os antecedentes e suas causas diretas que impedem o sucesso da gestão intrafamiliar no processo sucessório, pela compreensão dos fatores dificultadores na sucessão. O modelo proposto sugere uma cadeia de causalidade com fatores que podem dificultar o sucesso da sucessão (MASSIS; CHUA; CHRISMAN, 2008).

Tsabari e Weiss (2013) investigaram o impacto da má comunicação interpessoal durante a transição do processo de sucessão em um estudo de caso e os resultados mostraram que a comunicação deficiente ocasionou divergências e confrontos entre o fundador, o sucessor e os demais envolvidos, por conseguinte, isso reduziu a harmonia familiar durante o processo de sucessão. Tsabari e Weiss (2013) denominam essas situações de "armadilhas da comunicação". A pesquisa realizada pelos autores mostrou, ainda, como uma comunicação inadequada dificulta no processo de transição, acarretando efeitos psicológicos, mesmo quando os indivíduos envolvidos compartilham as mesmas atitudes, prioridades e interesses (TSABARI; WEISS, 2013).

\subsection{FOCOS DE CONFLITO DO PROCESSO SUCESSÓRIO}

Os conflitos ocorridos do processo de sucessão não são incomuns, uma vez que esse processo é bastante delicado. Frequentemente, as empresas enfrentam diferenças no modelo de gestão entre o sucessor e o sucedido (GRZYBOVSKI, 2007). É comum, ainda, o fato de que o reflexo das questões emocionais não resolvidas no âmbito familiar seja transmitido ao processo sucessório sob a forma de vaidades, de chantagens e de disputas (BERNHOEFT, 1989). O processo de sucessão envolve, além dos indivíduos familiares, os funcionários que não são da família (LAM, 2011). Além do mais, essa questão é considerada, na maioria das vezes, mais como um problema emocional que pode acarretar em sérios conflitos na empresa (MERWE; VENTER; ELLIS, 2009; LAAKONEN; KANSIKAS, 2011).

Focando na redução desses conflitos, Van Der Merwe, Venter e Ellis (2009) e Aguilera Revista Eletrônica de Estratégia \& Negócios, Florianópolis, v.11, n. 1, mai./ago. 2018. 
e Crespi-Cladera (2012) acreditam que o ideal é planejar a sucessão antes que a geração mais jovem adentre o negócio. Nesse sentido, é essencial que as questões acerca do processo sucessório sejam tratadas de forma mais racional e programada, permitindo uma gestão proveitosa.

Dos diversos tipos de conflitos em empresas familiares que são mencionados pela literatura, Passos et al. (2006) trazem à baila os seguintes: pendências do passado; conflitos de lealdade; educação para a cooperação ou competição, para o pensamento como sócio e para a dependência ou independência; padrão de comunicação; e atitude em relação às diferenças, aos conflitos e aos ressentimentos.

Para Gallo (2004), é natural que os empresários que conseguiram promover e desenvolver a sucessão de forma exitosa em sua empresa desejem que ela se torne uma estrutura de apoio para as atividades educativas e econômicas de sua família. Dessa maneira, a maior finalidade da empresa é confundida com os interesses familiares, que podem provocar vários problemas nas empresas familiares, por exemplo, a confusão entre os objetivos da família e os da empresa. É importante mencionar que algumas famílias tendem a crescer mais rápido do que a empresa da qual são sócias, criando uma situação de alternância de interesses envolvidos nesse processo, portanto, os interesses familiares podem, então, ficar em desacordo com os interesses do negócio.

\section{PROCEDIMENTOS METOdOLÓGICOS}

Neste estudo foi realizada uma pesquisa qualitativa, com objetivo de analisar os aspectos facilitadores, dificultadores e principais focos de conflitos, que foram identificados para a condução dos processos de sucessão em uma empresa familiar. A construção desta pesquisa realizou-se no grupo WEG S/A., empresa familiar de grande de impacto, que se encontra na sua terceira geração e já vivenciou dois processos de sucessão. Essa condição é benéfica, pois dessa maneira é possível analisar as reconfigurações de um case de sucesso num contexto familiar, que desde cedo preocupou-se com o processo sucessório.

Optou-se pelo estudo empírico realizado por meio do método de estudo de caso único, que representou a análise de uma unidade de estudo, visando um exame detalhado do ambiente, dos sujeitos envolvidos e de um fenômeno particular da organização, com 
enfoque descritivo, pois teve a intenção de mapear uma realidade e descreveu as suas características.

Para a realização desta pesquisa, o critério para seleção da amostra da organização participante seguiu as seguintes etapas de seleção: (i) empresa de caráter familiar; (ii) organização que possui o processo de sucessão planejado; (iii) já vivenciou o processo de sucessão familiar; e (iiii) organização que poderá servir de modelo e de exemplo ao se tratar de sucessão familiar para outras empresas familiares. No que se refere à justificativa para a pesquisa de estudo de caso único, se tomou como motivação as cinco justificativas de Yin (2010), dentre as cinco justificativas destaca- se a terceira: para o caso único é quando o caso é representativo ou típico. Portanto, a escolha da organização WEG, como objetivo deste estudo único, foi motivada pelas justificativas de Yin (2010).

Com relação a análise de dados esta investigação usufruiu da análise de conteúdo e análise de narrativa. Logo, o processo de interpretação e análise dos dados, envolveu primeiramente preparação dos dados para análise, extraindo sentido dos dados dos textos, aprofundando-se nos processos de compressão, abduzindo na integra as evidências narradas pelos entrevistados, cruzando as informações das entrevistas com os dados documentais disponibilizados e observação.

Foram coletados dados a partir da pesquisa documental e de entrevistas, sendo dados secundários e primários. Utilizou-se de roteiros de entrevista semiestruturados. As entrevistas foram feitas de forma presencial, gravadas conforme autorização dos entrevistados e transcritas na íntegra. A realização das empresas concedeu-se em ambientes diferentes durante os meses de abril e julho de 2016, com duração média de uma hora e meia cada entrevista, totalizando nove horas e cinco minutos. Além das entrevistas foram coletados documentos internos da empresa, como, regimento sobre a direção de uma empresa familiar, livro que relata a implantação do primeiro processo sucessório, textos narrando a história da organização e a gestão de seus fundadores, planejamentos traçando etapas para a realização do processo sucessório, registro, definições de papéis, entre outras informações disponibilizadas pela empresa pesquisada, além do website da organização. A seleção dos respondentes ocorreu depois da primeira entrevista e da inspeção de documentos e informações via website do objeto desse estudo. No decorrer 
da análise nas narrativas, os entrevistados são nominados por codinomes.

\section{ANÁLISE E DISCUSSÃO DOS RESULTADOS}

Esta seção apresenta a percepção das informantes chaves acerca dos processos facilitadores da sucessão de empresa familiar, da organização estudada, bem como as principais dificuldades e focos de conflito.

\subsection{FACILITADORES DA SUCESSÃO FAMILIAR}

Dentre os aspectos facilitadores, observou-se que a empresa estudada dispõe de vários deles para a condução dos processos sucessórios. Para melhor explanar os principais facilitadores identificados, segue Figura 1.

Figura 1- Aspectos facilitadores dos processos sucessórios.

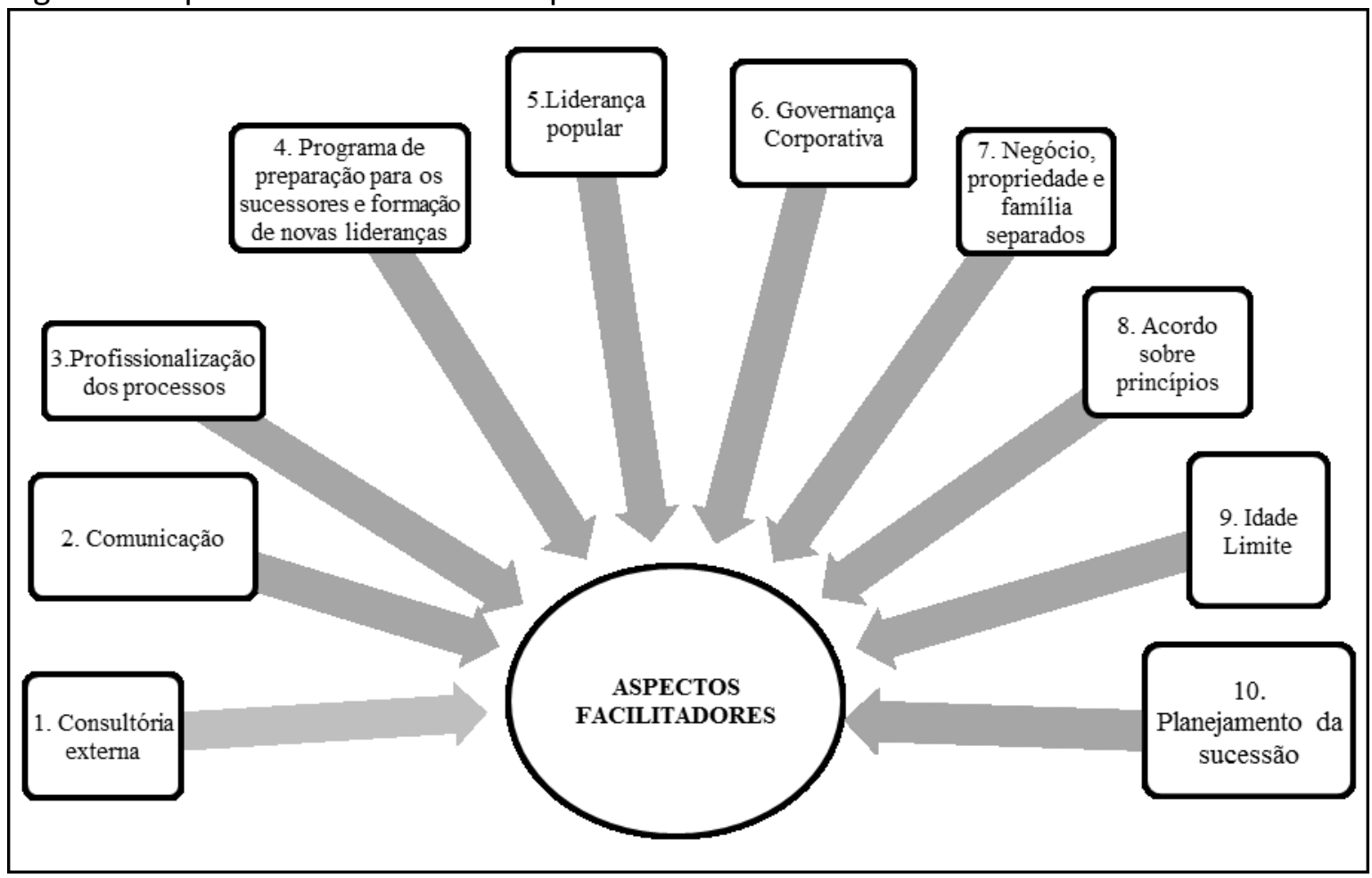

Fonte: Elaborado pelos autores (2017).

Nota-se que o primeiro aspecto citado por quase todos os entrevistados é a presença das empresas de consultória, especializadas no assunto, vista por eles como um dos principais fatores facilitadores. Começando pela consultoria do professor João Lodi, a qual foi fundamental para empresa organizar sua estrutura e preparar suas novas gerações em suceder uma empresa familiar, mas com caráter profissional, sem influenciar ou prejudicar o Revista Eletrônica de Estratégia \& Negócios, Florianópolis, v.11, n. 1, mai./ago. 2018. 
percurso no decorrer dos anos dessa organização. Já no segundo momento, a presença da empresa americana de consultoria foi mencionada também pelos entrevistados por facilitar a escolha e a avaliação dos candidatos, pois confirmou a seleção adequada nas qualificações dos candidatos por meio de seus métodos de avaliações, concedendo à organização segurança e demonstrando aos candidatos suas potencialidades e fragilidades a serem supridas; logo se observa que não é apenas a empresa que está demonstrando suas fragilidades, mas sim pessoas de fora, o que torna mais simples para os pretendentes entenderem e aceitarem que ainda não estão prontos. Estol e Ferreira (2006) corroboram com a ideia ao afirmar que um processo sucessório pode gerar traumas dependendo da maneira como é conduzido e se é aceito pelos envolvidos.

O Quadro 1, demostra o relato dos entrevistados, sobre o primeiro aspecto facilitador.

Quadro 1 - Percepções dos entrevistados

\begin{tabular}{|l|l|}
\hline Entrevistado A & $\begin{array}{l}\text { O melhor que foi feito, quando nós contratamos o Lodi aqui, e o seu Eggon disse agora } \\
\text { está na hora da sucessão, o primeiro trabalho dele foi mais simples do que agora, pois } \\
\text { agora foi feito com a consultoria dos americanos, mas ele também já tinha a ideia da } \\
\text { liderança, como era aceito pelas gerências e como ele faz reunião - porque nós temos } \\
\text { aqui cada sexta-feira a reunião da diretoria da WEG S/A. }\end{array}$ \\
\hline Entrevistado C & $\begin{array}{l}\text { Esse agente externo, eu diria, que seria um facilitador que também reverenda o que } \\
\text { você está pensando ou até muda, e nós tivemos várias mudanças aqui mesmo na área, } \\
\text { a gente está falando da sucessão da presidência, mas na sucessão de diretores, de } \\
\text { gerentes, o processo é exatamente o mesmo, vem desde de lá de cima [...] Eu diria que } \\
\text { sempre esse facilitador externo é fundamental. }\end{array}$ \\
\hline Entrevistado D & $\begin{array}{l}\text { Facilitadores que nós tivemos foram os consultores quando tinha qualquer assunto que } \\
\text { poderia gerar uma polêmica qualquer. O Sr. Eggon admitia uma consultoria para evitar } \\
\text { qualquer conflito, a consultoria analisava sobre o aspecto racional e não sobre o } \\
\text { aspecto emocional e essas conclusões das diversas consultorias que nós tivemos levam } \\
\text { a isso para os três e acima disso tomávamos decisões novamente racionais esquecendo } \\
\text { os aspectos emocionais né, então isso foi um facilitador. }\end{array}$ \\
\hline Entrevistado F & $\begin{array}{l}\text { [...] acho que as consultorias buscadas pela WEG ajudaram muito sabe, principalmente } \\
\text { no começo [...] }\end{array}$ \\
\hline
\end{tabular}

Fonte: Elaborado pelos autores (2017).

Outro aspecto facilitador citado pelos entrevistados, foi o quesito comunicação e transparência em transmitir as informações nos processos, pelo fato de a empresa possuir uma gestão compartilhada, automaticamente a comunicação é gerida, consequentemente ocasionando credibilidade e confiança por todos os envolvidos. O fator transparência é notado pelo fato de a organização ter sido clara, correta no processo de escolha de seus sucessores e no momento próximo da transferência da sucessão ter anunciado para todos os colaboradores, clientes e fornecedores, antes mesmo que os boatos e as controvérsias se Revista Eletrônica de Estratégia \& Negócios, Florianópolis, v.11, n. 1, mai./ago. 2018. 
formassem, tornando o processo de sucessão mais acessível e resguardando-se de inverdades e de possíveis zonas de conflitos, principalmente por parte dos participantes diretos. Scheffer (1995), Le Breton-Miller et al. (2004) e Michael-Tsabari e Weiss (2013) contribuíram ao afirmar que a definição de um plano de comunicação conduz o compartilhamento de notícias sobre a sucessão para as partes interessadas, por exemplo, os colaboradores, os fornecedores, os clientes e os acionistas no caso da WEG, incluindo a distribuição a quem tem a responsabilidade de emitir as comunicações relacionadas com a sucessão.

O terceiro facilitador mencionado foi a profissionalização dos processos, estabelecidos pelos fundadores, muito tempo antes do primeiro processo de sucessão ocorrer, com ajuda da consultoria mais a gestão e a intuição de Eggon, pois o objetivo foi estabelecer e estruturar para longo prazo processos bem definidos para que em momentos futuros a companhia não ficasse na dependência de seus fundadores e herdeiros, válidos para todos os cargos de gestão, de acordo com relato do entrevistado a seguir. Nota-se que pelo fato de os fundadores terem se precavido ao transformar a WEG de empresa familiar para uma empresa profissionalizada foi um dos grandes facilitadores para que os processos ocorressem da melhor forma possível por meio de diretrizes claras reduzindo o risco de conflitos e rejeições.

No segundo processo de sucessão (gestão Décio), complementou-se, uma vez, que se aprimorou o regime de encontros das famílias com objetivo de mostrar o direcionamento paras as futuras gerações exclusivamente para as posições de acionistas, deixando a parte de gestão para os profissionais não membros das famílias, já que a organização retém muitos profissionais qualificados e preparados, consequência da forma como foi estruturada a empresa na parte de avalição e desempenho de profissionais. O estudo de caso realizado por Oliveira, Albuquerque e Pereira (2012), na empresa Randon S/A, mostra semelhanças na forma com que aquela organização profissionalizou seu processo de sucessão e também evidenciou as facilidades consequentes.

Porque o Eggon preparou isso não tinha mais a dependência de pessoas, os processos eram discutidos, os processos eram bem conhecidos, os processos decisórios eram bem estabelecidos, não tinham decisões isoladas, todas as decisões eram em equipes de forma geral, então diria o processo decisório, sucessório estava bem encaminhado em todos os níveis [...] antigamente o pessoal 
não acreditava e comentava: se sair o Eggon, morre a WEG. Digo ora, Eggon, Geraldo e Werner podem ficar fora, pois, a estrutura da dentro da WEG é tão grande tão bem formada que nem um compressor vai parar em função do falecimento de alguém, e como ele dominava toda parte da gestão, isso facilitou bastante, eu acho, a estrutura (ENTREVISTADO D).

Observa-se que pelo fato de os precursores terem profissionalizado a estrutura da companhia, o incentivo de criação e a formação de novas lideranças se tornaram consequência dessa estrutura; verificada como facilitadora para a condução dos dois processos de sucessão, uma vez que o sistema de avaliação e preparação dos candidatos tornou-se metódico e cauteloso, ignorado por grande parte das empresas familiares, principalmente as de menores portes e alguns casos por grandes empresas como pode ser citado: os processos da Azaleia e da empresa TAM.

Minadeo et al. (2009) realizaram um estudo, com objetivo de contextualizar e de comparar os processos sucessórios das empresas Azaleia e TAM, a fim de discutir suas consequências para a continuidade dos negócios. Eles constataram que ambas foram pegas de surpresa pelos seus fundadores, os quais não haviam se preocupado a longo prazo em preparar seus sucessores, assim como profissionalizar e estruturar suas empresas. O fundador da Azaleia foi surpreendido por uma doença grave, ele por seis meses ainda conseguiu preparar seu sucessor, porém não foi o suficiente, nesse mesmo período, a empresa passou por dificuldades, devido à situação econômica presenciada naquele momento e, após a sua morte, isso contribuiu e acelerou para a venda da organização.

Já no caso da TAM, segundo Minadeo et al. (2009), a sua sucessão ocorreu sem planejamento e sem preparação de um sucessor, por causa da morte inesperada de seu presidente em um acidente, coincidentemente num período considerado muito crítico devido à crise da aviação mundial, e que foi agravado no Brasil pelo surgimento de outras companhias aéreas com estratégias de mercado e preços diferenciados (no estilo lowcost low fare), tirando a companhia da posição de liderança que ocupou por muito tempo, para posições inferiores para aquele período, levando a companhia a tomar estratégias emergentes, o que dificultou devido ao fato da organização não ter preparado seu futuro sucessor, isso ocasionou situações turbulentas e afetou diretamente os negócios da companhia. Percebe-se que concomitantemente, a WEG, também, enfrentou no início das sucessões de Décio e Harry problemas macroeconômicos, os quais foram superados de 
forma exitosa por conta do preparo e da formação que eles receberam de forma planejada pelos seus antecessores, visto pelos entrevistados como um grande facilitador para os processos de sucessão.

Para realizar todo esse processo, leva questão de anos, a parte do Décio deve ter [...] é claro todos esses são preparados, por isso, eu digo na nossa empresa muita gente é preparada para escolher um ou dois, então tu não fica só preparando um ou dois, com esse rodízio que nós fizemos de funções, como as pessoas conhecem muito as coisas, então tu tens muitos candidatos, tu prepara muitos candidatos é isso fica bem mais fácil no processo de sucessão [...].e isso você faz durante a carreira, mas é evidente que tem lá um período de três anos quando tu colocou na ideia que daqui um tempo vai haver a sucessão, se dá um tempo de três anos, já começa a definir um pouquinho quem seriam os candidatos [...] (ENTREVISTADO C).

Correspondentemente ao sistema de avaliação dos candidatos ser complexo e robusto, automaticamente nessa avaliação já é verificada a popularidade dos futuros sucessores, visto, pelo entrevistado B, como um facilitador do processo de sucessão, uma vez que o apoio e a ajuda múltipla dos demais diretores e gestores é primordial para facilitar a administração do novo sucessor, o que na sua visão implicaria de primeiro momento o caso de um sucessor selecionado fora da organização, o qual ao iniciar sua gestão teria que conhecer a cultura e os valores da companhia e cativar sua equipe e, ao mesmo tempo, gerir a empresa de tamanha dimensão como é o caso da WEG.

O sexto aspecto facilitador mencionado para propiciar o processo de sucessão foi a concepção do conselho e Pereira (2012) concordam com isso ao afirmar que a implementação de mecanismo administrativo e do conselho de família criados e formalizados a partir da governança corporativa. Oliveira, Albuquerque de governança facilita o processo de sucessão, uma vez que seja efetuada a profissionalização na empresa familiar, o que demanda alterações na estrutura de propriedade e de controle, ou seja, especificando a distribuição dos direitos entre os diferentes participantes, por exemplo, o conselho de administração, os diretores e os acionistas. Repara-se que, com a constituição do holding, asseverou-se que aspectos familiares fossem separados das questões patrimoniais e profissionais, isolando as organizações do grupo de eventuais desavenças internas.

O sétimo aspecto facilitador citado foi o fato de a empresa ter bem separado desde o seu início, família, propriedade e gestão; estruturando sua gestão e formalizando com seus Revista Eletrônica de Estratégia \& Negócios, Florianópolis, v.11, n. 1, mai./ago. 2018. 
familiares, para que possíveis desavenças e zonas de conflitos não surgissem no decorrer de seu percurso. Visto que a empresa é formada por três familiares diferentes e encontra-se na sua terceira geração, observou-se tanto nos documentos internos como nos relatos dos entrevistados que "[...] negócio é negócio e família é família [...] quando o sócio entendedor da área fala e se dois concordavam, o terceiro não contrariava". Outro fato advertido é que a empresa estabeleceu regras com relação a não realização de compras de empresas dos familiares não pertencentes ao grupo. Ficou claramente explícito que família e negócios são extremamente separados na WEG, o que mais tarde veio a somar com a criação da Holding por meio da governança e com o acordo de princípios estabelecidos anos antes da primeira sucessão.

Observa-se que o regimento de acordos e princípios, criados pelos fundadores desde os primórdios da organização, contribuiu para facilitar os processos sucessórios, uma vez que a WEG é uma empresa profissionalizada e gerida conforme seu regimento (Acordo de princípios, Anexo A) por profissionais capacitados e qualificados independentemente de ser ou não familiar. Seus familiares foram e são educados para agirem conforme seus próprios desejos e sua verdadeira vocação, e de fato são instruídos a começar da infância a serem acionistas. Como as regras do acordo de princípios são sempre seguidas, isso contribuiu para facilitar os processos de sucessão. Scheffer (1995), na sua segunda ação preventiva para facilitar o processo de sucessão, menciona sobre a fixação de critérios claros por meio de princípios concordando com o facilitador citado.

O nono aspecto facilitador observado foi a idade e o plano de aposentadoria estipulado para entrada e, saída do sucessor, visto que a literatura nos mostra que há um ponto dificultador na questão de o antecessor desligar-se e transferir a sucessão em muitas organizações. Coma idade limite estipulada para aposentaria e ou afastamento da direção executiva é vista como um facilitador, uma vez que o antecessor está se auto preparando antecipadamente em transferir sua posição com livre arbítrio, sem interferir no novo modelo de gestão do sucessor, dando espaço para sucessores mais jovens ocuparem a posição com novas ideias e projetos, e mais energia típica do fator natural do ser humano. Scheffer (1995) e Ferreira (2015) reforçam essa ação ao constarem em suas pesquisas que o fator idade é levado em consideração dentro de um plano de sucessão, que quanto mais próximo da aposentadoria, mais notória é a consciência do executivo de se ver apenas como Revista Eletrônica de Estratégia \& Negócios, Florianópolis, v.11, n. 1, mai./ago. 2018. 
sucedido, e sendo favorável a ceder espaço aos jovens; os próprios executivos perto da sua aposentadoria entendiam que, quanto mais jovem era o candidato à posição de sucessor, mais próximos os avaliadores estariam da condição de sucedidos ou futuros sucedidos.

O último aspecto e grande facilitador observado, foi o planejamento da sucessão a longo prazo, visto que, para o primeiro processo, a empresa se planejou 13 anos antes; repara-se que, para esse planejamento, houve a preocupação, a percepção e a intuição dos fundadores em estruturar a organização por meio da horizontalização de processos gerenciais quando estava em voga terceirizar processos, porém, eles tiveram essa visão a longo prazo e incentivaram a formação e a preparação de novas lideranças para mais tarde tornar o processo de sucessão de uma empresa familiar em uma sucessão profissionalizada, por meio da estipulação e da amarração com o propósito do acordo de princípios, tratando como seria a gestão dali para frente de uma empresa familiar. É importante salientar que a afirmação de que a WEG constitui uma empresa de controle familiar, mas de gestão profissional, encontra-se fortemente veiculada nos discursos dos entrevistados.

\subsection{DIFICULTADORES DO PROCESSO SUCESSÓRIO}

Identificou-se que a empresa estudada possui mais aspectos facilitadores do que dificultadores. Ao contrário do que a literatura menciona, é alto o índice de empresas que não ultrapassam duas gerações, e isso se deve a: fatores individuais, relacionais, financeiros de contexto macro e microambiente, e de processos, conforme pesquisa de De Massis, Chua e Chrisman (2008).

Analisa-se que pelo fato de os processos sucessórios terem sidos planejados, profissionalizados, estabelecidos parâmetros, e estipulados acordos de princípios, seguidos de regime de avaliações robustos, programas de preparação e formação de lideranças metódicas e a sólida condição financeira da organização, facilitou bem mais do que dificultou.

No entanto, dentre os dificultadores abordados pelos entrevistados, é possível destacar:

a) Diretores da companhia são muito visados por outras organizações; 
b) Existência de um grande número de gestores preparados, o que dificulta o processo de seleção;

c) Dificuldade com relação a fatores individuais relativo a aceitação da indicação por parte de outros candidatos preterido no primeiro processo de sucessão.

d) Dificuldade no aceite de informações, tendo que ter validação de consultores externos.

Conforme narrado pelos entrevistados:

\begin{abstract}
Eu acho [...] nós somos sempre muito assediados para tirar gente da WEG sabe, agora tu vê a WV, eles são loucos para pegar gente daqui [...], mas como nós temos uma cultura muito forte e somos uma das primeiras empresas, acredito que em 94 foi [quando] começou a participação dos lucros com os empregados [...] (ENTREVISTADO A).

O que é dificultador é a gente ter muitos candidatos, muitos líderes (risos) preparados, bons líderes preparados eu acho que isso é o dificultador. O dificultador é a gente escolher entre os bons, acho que isso é o pior, isso é o mais dificultoso e o restante, sem sombra de dúvidas, o que for escolhido é o melhor dos melhores (ENTREVISTADO E).
\end{abstract}

Verifica-se que o primeiro dificultador está relacionado ao macroambiente, devido ao fato da companhia deter vários profissionais qualificados, preparados, entre eles supostos candidatos a sucessores. Esses, por sua vez, acabam recebendo propostas tentadoras para trabalharem em outras empresas, dificultando que a WEG retenha esses profissionais, uma vez que foi investido estrategicamente na qualificação e na preparação deles.

O segundo dificultador apontado tem relação ao grande número de gestores preparados, em parte, por causa da política da organização em desenvolver e preparar novas lideranças a longo prazo. Observa-se que o processo de formação dos candidatos acaba sendo um obstáculo na hora de selecionar o sucessor. Pois por mais que empresa possua um sistema robusto de avaliação, há o risco de perder algum profissional por acreditar que ele está suficientemente preparado para ser o novo sucessor, o que de fato ocorreu no primeiro processo de sucessão, conforme relatado pelo entrevistado A.

O terceiro dificultador está relacionado ao aceite de supostos candidatos no primeiro processo de sucessão, já que se diziam capazes e não admitiram que ainda lhes faltava "algo" para ser lapidado antes de assumirem; esse dificultador é notado como um embaraço Revista Eletrônica de Estratégia \& Negócios, Florianópolis, v.11, n. 1, mai./ago. 2018. 
na passagem da primeira sucessão, sendo que entre esses dois candidatos, um deles era membro da família e o outro profissional interno que detinha quase três décadas de experiência e vivência na companhia.

Uma zona de conflito foi estabelecida no primeiro processo, uma vez que candidatos preteridos, não aceitando a desclassificação, se decepcionaram com a empresa, a tal ponto que um solicitou sua transferência para uma unidade da companhia no exterior e o outro acabou se desligando da empresa. Logo, subentende-se que se ambos foram classificados para assumir o posto de sucessor da diretoria executiva, pois eram profissionais qualificados que ocupavam posições estratégicas dentro da companhia. Com a saída inesperada dos candidatos não escolhidos e com a decisão tomada pelos mesmos, levou a necessidade de uma substituição na vacância dos cargos, o que certa forma gerou certo desconforto na passagem da primeira sucessão.

O quarto dificultador tem relação com a passagem das informações no decorrer dos processos. Há certa resistência por parte dos candidatos em acatar algumas informações, o que pode ser interpretado como uma falha de comunicação no modo como são direcionadas essas informações. Tsabari e Weiss (2013) recomendam o uso de consultores externos para auxiliar a transferência de informação e reduzir o que ele chama de "armadilhas da comunicação". Os resultados da pesquisa de Tsabari e Weiss (2013) demonstraram que a comunicação deficiente leva a divergências e a confrontos entre os envolvidos no processo de sucessão.

\subsection{FOCOS DE CONFLITOS NOS PROCESSOS SUCESSÓRIOS}

Com relação aos conflitos, verifica-se que no primeiro processo houve maior predisposição na ocorrência deles, visto que alguns foram amputados no seu foco, com o objetivo de não os disseminar em outros setores da empresa. Entre os citados, percebe-se mais os de ordem familiar, relacionados com os próprios membros da família. Apesar de esse foco de conflito não estar diretamente ligado aos processos de sucessão, verificou-se que tais processos são primordiais para o fortalecimento dos valores e da cultura da instituição. O objetivo dos fundadores era tornar a WEG uma empresa de cunho familiar, mas administrada por profissionais e, independentemente do grau de parentesco, o que deveria prevalecer sempre na organização é o profissionalismo e o respeito mútuo, sejam Revista Eletrônica de Estratégia \& Negócios, Florianópolis, v.11, n. 1, mai./ago. 2018. 
filhos/filhas ou quaisquer profissionais sem vínculo sanguíneo.

\begin{abstract}
Uma filha [do] seu Eggon [...] estava trabalhando no recursos humanos, [disseram] para o pai, o chefe dela [que falou com o pai dela] então, ele chamou outras pessoas e disse: vocês vão ver esses casos aqui, foi lá, então a moça que era chefe dela, que era chefe do setor, disse: [...] eu tenho que muitas vezes chamar atenção, porque ela [...] quer mandar aqui [...], opa, aí o Eggon mandou chamar o gerente da área, olha minha filha está na tua seção, departamento, você tem visto [ou] ouvido alguma coisa da minha filha? É, a chefe já me falou que está muito difícil de controlá-la e tudo mais e tal [...] Bom, ele chamou ela [lá]em cima, você vai pedir demissão e fazer outra coisa, ela ficou sem falar com o pai dez anos, sabe que tem essa coisas né, mas se não tivesse feito já começava uma coisa sem parar [...] (ENTREVISTADO A).
\end{abstract}

Averiguou-se que a primeira zona de conflito vivenciada foi de pai para filha, devido ao fato de a herdeira não agir de forma profissional, misturando trabalho com poder, o que levou ao desligando dela da organização e, junto com isso, houve certo desentendimento familiar, o que influenciou a vida pessoal dos dois. No entanto, percebe-se a preocupação do pai como gestor em agir profissionalmente pensando não somente no relacionamento entre as partes, mas na empresa e no exemplo de deveria ser dado naquele momento. O fundador se preocupou em se precaver e seguir de fato com o que havia acordando entre os demais sócios: o de tornar a WEG uma grande empresa sem a influência de desentendimentos e conflitos familiares, separando o lado pessoal da gestão. Gersick et al. (2006) e Merhi et al., (2010) mencionam que as fontes de conflito recorrentes em empresa familiares devem ser diagnosticadas e tratadas como algo proveitoso, pois é tarefa do pai intervir e conciliar, amenizando as situações na iminência de conflitos.

A postura do fundador com relação à posição que a herdeira ocupava dentro da organização se diferente dos achados constatados na pesquisa de Teixeira e Carvalhal (2013). Os autores mencionam que pelo fato de a sucessão ser informalmente planejada, os herdeiros são testados ocupando posições de alta responsabilidade ainda muito jovens, antes mesmo de quaisquer experiências profissionais internas ou externas.

O segundo foco de conflito referendado está ligado ao primeiro processo de sucessão, já mencionado como um dificultado, observou-se que gerou estratégias emergentes para o novo presidente executivo. Mesmo tendo sido preparado antecipadamente, o mesmo não dispunha de experiência presidencial, sendo tratado com um desafio a mais a ser vencido, o que não estava dentro do planejado. Com o amparo do 
conselho de administração, que mesmo não intervindo diretamente, foi encarado como um pequeno dificultador que gerou focos de conflitos inesperados, tanto de ordem familiar bem como de ordem profissional, dado ao fato que ambos estavam concorrendo ao cargo de sucessor, mas não possuíam as devidas atribuições exigidas para aquele momento.

Conflito, isso sempre acontece, acho que é da natureza humana, é você se frustrar e dizer: pô não fui escolhido, então houve, na época do Décio, [...] um diretor que depois até saiu da empresa porque achava que podia, era direito dele assumir e ele saiu da empresa e foi galgar outras colocações, mas quando o Harry assumiu, nada disso aconteceu, não aconteceu esse grande conflito, mas lógico há todo um tempo de passagem (ENTREVISTADO C).

Apurou-se também que, no início do processo de transformação de empresa familiar para empresa profissionalizada, havia resistências e pequenos focos de conflitos com relação às mudanças cobradas, mas com a presença do Sr. Baumer, o trabalho desenvolvido por ele, na época vice-presidente da organização, e o apoio mutuo dos sócios, os problemas foram sanados. Analisa-se que esses focos de resistências e conflitos não estavam diretamente ligados com os processos sucessórios, mas a longo prazo eles contribuíram para dar ênfase aos processos sucessórios. Tal fato se deu porque cada ser humano possui um modo próprio de gerir e é natural que mudanças sejam realizadas e acionadas; e por já estar incorporado na cultura organizacional, é visto apenas como mais um desafio a ser encarado pelos demais colaboradores, precavendo-se assim de possíveis resistências e conflitos.

Verifica-se que a maioria dos entrevistados não menciona e não sabe responder se de fato surgiu algum conflito, além dos já mencionados. Mas nas entrelinhas pode se observar que talvez não houvesse intenção deles apontar se realmente algum caso tivesse ocorrido. Percebeu-se que foram citados alguns focos de conflitos apenas no primeiro processo de sucessão, já no segundo processo os entrevistados não deixaram evidente em momento algum.

A ausência de possíveis focos de conflitos no segundo processo sucessório pode ser justificada a partir do relato do entrevistado $D$, uma vez que os fundadores estavam preocupados em profissionalizar a empresa para reger o controle. Mediante essa posição desde o seu início, a empresa já apresentava aspectos de governança corporativa, o que motivou mais tarde a criação da Holdings. Observa-se que a empresa foi estruturada, pensada desde sua fundação, e o fato de as sucessões terem sido planejadas, com a 
formalização da governança corporativa e a criação do conselho de família, reduziu as chances de conflitos. Nota-se que os focos de conflitos ocorridos na primeira sucessão foram sanados estrategicamente para que não se repetissem no segundo processo de sucessão.

Torna-se claro que a organização estudada dispõe de muito mais facilitadores do que dificultadores, uma vez que a sucessão foi pensada e planejada 13 anos antes de acontecer o primeiro processo de sucessão. Por apresentar mais facilitadores do que dificultadores é notório a baixa ocorrência de focos de conflitos em ambos os processos, devido ao preparo que as famílias, os herdeiros e os profissionais receberam antes de acontecer a primeira sucessão, o que formalizou e otimizou posteriormente com a criação do conselho de família. O fato de a empresa estar há 55 anos no mercado e desde o início ter separado negócio, propriedade e família, contribuiu com sua longevidade e, principalmente, a precaução de evitar conflitos e desavenças entre os familiares, uma vez que se trata de três famílias distintas, com culturas e valores diferentes e que jaz na sua terceira geração. Outro fator citado como sendo primordial para que os processos sucessórios obtivessem êxito e sem maiores dificultadores e focos de conflitos foi a formação, desenvolvimento dado para seus familiares, a partir dos primeiros anos da empresa.

\section{CONSIDERAÇÕES FINAIS}

A pesquisa desenvolvida teve o propósito de analisar os aspectos facilitadores, dificultadores e principais focos de conflito do processo sucessório da WEG. Para tal, investigou-se como ocorreram os dois processos sucessórios legitimados em uma organização multinacional, caracterizada familiar, conduzida por três famílias de diferentes laços sanguíneos e, logo, de culturas distintas.

Dentre as estratégias identificadas, detectou-se que a maioria delas é vista como facilitadoras no decorrer dos processos. Apurou-se que pelo fato de a empresa ser familiar, mas tratada desde o princípio como uma empresa profissionalizada, ela estipulou estratégias, vistas como primordiais e facilidatoras na execução de longo prazo para as sucessões, entre elas: a forma como foram estipuladas as estratégias para evitar possíveis focos de conflitos de cunho familiar, o que normalmente é apresentado pela literatura como decorrente nas organizações familiares. Notou-se que esses possíveis focos de conflitos foram coibidos na sua base logo de início.

Revista Eletrônica de Estratégia \& Negócios, Florianópolis, v.11, n. 1, mai./ago. 2018. 
A profissionalização das gestões, desencadeada, constitui uma discussão relevante na literatura sobre empresas familiares, a qual é literalmente versada de forma limitada em pesquisas empíricas.

Perante o modo como foi estruturada a organização para receber suas futuras gerações, se verificou vários aspectos facilitadores significativos. Dentre as principais evidências desta pesquisa, o episódio de o tema processo sucessório ser visto pela organização pesquisada como um processo contínuo é interessante e não meramente um evento como é abordado por outras organizações e de acordo com o que a literatura nos apresenta. Pois esse processo já está incorporado na WEG, desde o primeiro diagnóstico realizado pelos fundadores por meio do suporte inicial de consultores especializados no assunto. O efeito de a empresa ser tratada como uma empresa profissional, somada com a criação e posteriormente, formalização da governança corporativa, desencadeou estratégias facilitadoras primordiais na execução do primeiro processo de sucessão que mais tarde foram aprimoradas para o segundo processo.

Constatou-se que o caso estudado apresentou abundantes facilitadores que foram indispensáveis para a condução dos processos, entre elas o planejamento sucessório a longo prazo, programa de incentivo e formação de lideranças incorporado na gestão estratégica da companhia, a maneira de avaliação traçadas para os futuros sucessores, a fomentação e a verificação em períodos de médio prazo de novos sucessores, o quesito idade limite e o plano de aposentadoria, nutridos com o timing do início dos processos, pois nos dois momentos o fundador e o antecessor souberam abrir espaço para a nova geração.

Outro facilitador expressivo constatado foi a maneira como as três famílias foram organizadas e preparadas. As ações promovidas através dos encontros de famílias desde a infância dos herdeiros, sendo reportados assuntos como: sobre o andamento da organização, como um membro poderia ingressar na empresa, indo além, como temas de formação pessoal e principalmente orientações em como gerir suas ações, ou seja, de modo bastante interessante, as decisões implementadas mostram claramente o direcionamento das futuras gerações exclusivamente para a posição de acionistas.

Essa pesquisa apresentou alguns aspectos limitadores, dentre eles: teórico e metodológico. Teórico, pois a grande maioria dos estudos que reportam a sucessão familiar Revista Eletrônica de Estratégia \& Negócios, Florianópolis, v.11, n. 1, mai./ago. 2018. 
tradicional, a que passa de pai para filho e, posteriormente, de filho para neto e ou sucessão realizadas com a contratação de profissionais externos a organização. Metodológica com relação à população entrevistada, fato que ocorreu, dado que não se conseguiu entrevistar o primeiro sucessor e dois herdeiros da segunda geração que figuram como membros do conselho de administração e conselho de família, devido à inviabilidade das suas agendas. Outro limitador adveio por não ter conseguido contato com as empresas que prestaram consultoria em ambos os processos, dado a questões de sigilos contratuais. Na primeira sucessão houve a contribuição do consultor e professor João B. Lodi, o qual veio a falecer, e com relação à segunda empresa especializada, por se tratar de uma empresa norteamericana, os pesquisadores não foram autorizados a contatar.

Destacadas as contribuições que o estudo permitiu alcançar, apresentados os principais limitadores, buscou-se direcionar a pesquisa para futuros estudos. A partir deste estudo foram delimitadas algumas ideias, que podem constituir pontos de partidas para novas investigações, enumeradas a seguir: Comparar o caso estudado com outras organizações que já passaram pelo segundo processo sucessório, consideradas de grande porte e de caráter familiar. Verificar como os critérios de avaliação se fazem necessários para o desenvolvimento de talentos na organização e quais aspectos devem ser considerados na estruturação do processo sucessório. Estudar a relação entre as estratégias adotadas de processo sucessórios em empresas familiares de pequeno e médio porte e comparar os resultados obtidos no presente estudo, analisando as discrepâncias e similaridades.

\section{REFERÊNCIAS}

AGUILERA, R. V.; CRESPI-CLADERA, R. Firm family firms: Current debates of corporate governance in family firms. Journal of Family Business Strategy, v. 3, n. 2, p. 66-69, 2012.

BERNHOEFT, R. A empresa familiar: sucessão profissionalizada ou sobrevivência comprometida. São Paulo: Nobel, 1989.

BUENO, J. C. C; FERNÁNDEZ, C.D.; SÁNCHEZ, A. V. Gestão da empresa familiar. São Paulo: Thomson Learning, 2007.

CRUZ MACHADO, R. M; WETZEL, U; RODRIGUES, M. E. A experiência de sucessão para herdeiras de empresas familiares do Rio de Janeiro. Cadernos EBAPE. BR, v. 6, n.3, p. 1-24, 2008. 
FAMILY BUSINESS NETWORK, Planejamento do processo sucessório . Disponível em: http://www.fbn-br.org.br/> Acesso em: 10 agos. 2016

FERREIRA, M. A. de A. Processo sucessório em organizações brasileiras: um estudo com uso de groundtheory. PhD Thesis. Universidade de São Paulo, 2015.

GALLO, M. A. Ideas básicas para dirigir la empresa familiar. Espana: Eunsa,2004.

GERSICK, K. E. De geração para geração. Gulf Professional Publishing, 2006.

GRZYBOVSKI, D. Plataforma de conhecimentos e aprendizagem transgeracional em empresas familiares.2007. 383 p. Tese(Doutorado em Administração) - Universidade Federal de Lavras, Lavras, 2007.

GUEIROS, M. M. B.; OLIVEIRA, L. M. B. de. Sucessão familiar: prática em empresa de transporte: uma visão dos dirigentes. In: ENCONTRO DA ANPAD, 2000, Foz do Iguaçu..Anais... Foz do Iguaçu: ANPAD, 2000.

HAUSWALD, H.; HACK, A. Impact of family control/influence on stakeholders perception. Family Business Review, v. 26, n. 4, p. 356-373, 2013.

LAAKONEN, A.; KANSIKAS, J. Evolutionary Selection and Variation in Family Businesses. Management Research Review, Bingley, v. 34, n. 9, p. 980-995, 2011.

LAM, W. Dancing to two tunes: Multi-entity roles in the family business succession process. International Small Business Journal, 2011.

LE BRETON-M, I., MILLER, D.;STEIER, L. P. Toward an integrative model of effective FOB succession. Entrepreneurship Theory and Practice, v. 28, p. 305- 328, 2004.

LEE, K., LIN, W.S.;LIN, G. H. Succession and Survival of Family Businesses. Proceedings 45은 ICSB. Brisbane, 2000.

LODI, J. B. Sucessão e conflito na empresa familiar. São Paulo: Pioneira, 1987.

LODI, J. B. A entrevista: teoria e prática. Pioneira, 1998.

MACHADO, H. P. V. Empresas familiares e a formação de sucessoras. In: ENCONTRO NACIONAL DOS PROGRAMAS DE PÓS-GRADUAÇÃO EM ADMINISTRAÇÃO-ENANPAD., 30., 2006, Salvador. Anais... Salvador, 2006.

MASSIS, A; CHUA, J. H.; CHRISMAN, J. J. Factors preventing intra-family succession. Family Business Review, v. 21, n. 2, p. 183-199, 2008.

MERWE, S. V. D.; VENTER, E.; ELLIS, S. M. An Exploratory Study of Some of the Determinants of Management Succession Planning in Family Businesses. Management Dynamics, Cape Town, v. 18, n. 4, p. 2-17, 2009.

MICHAEL-TSABARI, N; WEISS, D. Communication traps: Applying game theory to succession in family firms. Family Business Review, 0894486513497506. 2013. 
MINADEO, R; MELO, M. C. de O. L; RIBEIRO, C. M. TAM e Azaléia: processos de transição em empresas familiares DOI 10.5752/P. 1984-6606.2009 v9n20p114. Revista Economia \& Gestão, 9.20: 114-140. 2009.

OLIVEIRA, J. L.; ALBUQUERQUE, A. L; PEREIRA, R. D. De "filho do dono" a dirigente ilustre: caminhos e descaminhos no processo de construção da legitimidade de sucessores em organizações familiares. Revista de Administração, 2013, 48.1: 21.

PASSOS, É, et al. Família, família, negócios a parte: Como fortalecer laços e desatar nós na empresa familiar. 5. ed. São Paulo: Editora Gente, 2006.

PRICE WATERHOUSE, Empresa familiar o desafio da governança. Disponível em: https://www.pwc.com.br/pt/publicacoes/setores-atividade/assets/pcs/pesq-emp-fam14.pdf>. Acesso em: 15 agos. 2016

SALVATO, C; CORBETTA, G. Transitional leadership of advisors as a facilitator of successors' leadership construction. Family Business Review, 0894486513490796. 2013.

SCHEFFER, A. B. B. Fatores dificultantes e facilitadores ao processo de sucessão familiar. Revista de Administra \& ccdeilão da Universidade de São Paulo, v. 30, n. 3, 1995.

SHARMA, P. An overview of the field of family business studies: current status and directions for the future. Family Business Review, Boston, v.17, n.1, p.1- 35, mar. 2004.

TEIXEIRA, R. M; CARVALHAL, F. Sucessão e conflitos em empresas familiares: estudo de casos múltiplos em empresas na cidade de aracaju. Revista Alcance, v. 20, n. 3, p. 345-366, 2013.

VAN DER MERWE, S; VENTER, E; ELLIS, S M. An exploratory study of some of the determinants of management succession planning in family businesses. Management Dynamics, v. 18, n.4, 2009.

WARD, J. A sabedoria não convencional da empresa familiar. São Paulo, HSM Management n. 56, maio/junho 2006.

YIN, R. K. Estudo de caso: planejamento e métodos, tradução Ana Thorell, revisão técnica Cláudio Damacena. 2010. 